\title{
A Cognitive Study of Anger Metaphors in English and Kurdish
}

\section{Khalid Ali Abdullah}

English Department, College of Education, University of Raparin, Rania, Kurdistan Region, Iraq.

Email: bozhin@uor.edu.krd

\begin{abstract}
:
This article is a comparative study of anger metaphors in English and Kurdish from a cognitive linguistic perspective. Based on the Conceptual Metaphor Theory (CMT), the paper makes a comparative analysis of the conceptual metaphors of anger in English and Kurdish. The two languages are geographically and culturally unrelated. The study aims to find out similar and dissimilar points related to the way anger is conceptualized in English and Kurdish to show the universality and specificity of the different cultures. Also, the article looks for the causes of these differences and similarities so as to help people further understand the conceptualization of anger as one of the basic human emotions.
\end{abstract}

Keywords: Anger, Conceptual Metaphor, Conceptual Metonymy, English, Kurdish. 


\section{Introduction}

Human's body can be considered as a container for emotion. According to cognitive linguists, emotion is not just a thing that can be felt, but it is a kind of feeling that can be abstracted and experienced. To Ansah (2011: 29), emotion refers to the mental state that has bodily manifestation. Emotion concepts are conceptualized and they have conceptual structures. The conceptual structures can be embodied in terms of different things. For example, anger as one of the basic emotions can be conceived as heat, insanity, an opponent, an animal, a burden, a plant, a child, devil, bad smell or a bad taste.

\section{Method}

\subsection{Data collection}

A large number of metaphorical expressions used in describing anger in English and Kurdish. The English expressions were extracted from the works of Kövecses (1991), Lakoff (1987), Lakoff and Kövecses (1987) and Esenova (2009). Many expressions used in conceptualizing anger in English were illustrated in these works. The expressions were extracted from the English culture; containing everyday speech and written literary and traditional works like proverbs and poetry. The Kurdish expressions were extracted from the Kurdish culture, too; including everyday speech and idioms.

\subsection{Procedures}

First, the metaphorical expressions of anger in English and Kurdish were selected. Then the metaphorical expressions were classified according to the source domain they contain. After that they were explained qualitatively and exemplified in English and Kurdish. Kurdish metaphorical expressions were translated to English. Later, their conceptual mappings were described qualitatively. Finally, English and Kurdish samples were compared to each other to find out similar and dissimilar points related to the conceptualization of anger.

\subsection{Data analysis}

For this study the general methodology proposed by Kövecses (1986) and Lakoff and Kövecses (1987) in their work on anger has been complemented with Esenova's (2009) more detailed guidelines for identification and description of conceptual metaphor.

Kövecses (1986) and Lakoff and Kövecses (1987) analyze the most important metaphors used to express anger such as:

ANGER IS A HEAT OF FUID IN A CONTAINER

ANGER IS FIRE 
ANGER IS INSANITY

ANGER IS AN OPPONENT IN A STRUGGLE

ANGER IS A DANGEROUS ANIMAL

ANGREY BEHAVIOR IS AGGRESSIVE ANIMAL BEHAVIOR

ANGER IS A NATURAL FORCE

ANGER IS A CAPTIVE ANIMAL

ANGER IS A BURDEN

Esenova (2009) has recognized a set of metaphorical expressions that have been discounted in cognitive linguistic literature:

ANGER IS A HORSE

ANGRY BEHAVIOR IS AGGRESSIVE HORSE BEHAVIOR

ANGER IS A SNAKE

ANGER IS A PLANT

ANGER IS A CHILD

ANGER IS A DEVIL

ANGER IS A BAD SMELL / TASTE

\section{Conceptual metaphors of anger in English and Kurdish}

English and Kurdish are two unrelated languages. Anger, in English and Kurdish, as a conceptual domain, is experienced and conceived in terms of other experiential domains that have already been experienced. Langacker (1987: 147), Taylor (2002: 195) and Hamawand (2011: 265) explain the conceptual domain as a background knowledge in which our mental experiences are embodied. Moreover to Hamawand (2008: 17), linguistic phenomena are motivated by conceptual knowledge, which are grounded in experience. Since English and Kurdish are two different languages, language provides a mechanism for construal (Evans, 2006: 81). This means the same situation can be conceptualized differently by different speakers in different languages (Langacker 1987: 11, 110; 2010: 34). For instance, anger is conceptualized as a horse (ANGER IS A HORSE) in English, but, in Kurdish, it is conceptualized as a donkey (ANGER IS A DONKEY). To cognitive linguists, language is a lens in mind and it reflects the embodied nature of conceptual organization. They study language in the way that language manifests embodied conceptual structure (Evans, 2006: 81). Based on the Conceptual metaphor Theory (CMT), language is used to connect two different experiential domains in terms of resemblance (Cruse, 2000: 112). For instance, connecting ANGER with FIRE and connecting ANGER with INSANITY. The following anger metaphors are the most important ones in English and Kurdish: 


\subsection{ANGER IS HEAT}

The HEAT metaphor is very pervasive in languages. This metaphor is grounded in human's bodily parts. Most of the human's body parts are conceived as a container for emotion. Both English and Kurdish conceptualize anger in terms of heat. To Lakoff (1980), THE PHSYIOLOGICAL EFFECTS OF ANGER ARE INCREASED BODY HEAT. Given the metonymic principle that THE PHSYIOLOGICAL EFFECTS OF AN EMOTION STAND FOR THE EMOTION, we can get the conceptual metaphor: ANGER IS HEAT. Moreover, he (1987: 381-389) states that the physiological effects of anger are increased body heat, increased internal pressure (blood pressure, muscular pressure), agitation, and interference with accurate perception. When anger increases, its physiological effects increase. There is a limit beyond which the physiological effects of anger impair normal functioning.

Based on the metonymic principle THE PHSYIOLOGICAL EFFECTS OF AN EMOTION STAND FOR THE EMOTION, on the basis of appearance via the physiological effects we can get whether someone is angry or not. Thus, we can observe a system of metonymies for anger:

BODY HEAT:

1) Do not get hot under the collar.

INTERNAL PRESSURE

2) When he found out, he almost burst a blood vessel.

REDNESS IN FACE AND NECK AREA:

3) I got red with anger.

AGITATION:

4) Tom was shaking with anger.

INTERFERENCE WITH ACCURATE PERCEPTION:

5) I was blind with range. (Kövecses, 1990: 13)

The expressions (1-5) show the presence of anger via the assumptions of physiological effects.

Though, the conceptual metaphors may have the same source domain within different cultures. In English the metaphor ANGER IS HEAT has two versions. The first version of the metaphor is found where the heat is applied to fluids. The second version is found where the heat is applied to solids. When the heat is applied to fluids, we get: ANGER IS THE HEAT OF A FLUID IN A CONTAINER. The motivation for this consists of the HEAT, INTERNAL PRESSURE and AGITATION which are parts of the physiological effects. On the other hand, when ANGER IS HEAT is applied to solids, we get the second version which is ANGER IS FIRE. The second version is motivated by the HEAT and REDNESS aspects of the physiological effects (Lakoff, 1987: 383).

Lakoff and Kövecses (1987a: 383) state that the metapor ANGER IS THE HEAT OF A FLUID IN A CONTAINER is the central metaphor in the conceptualization of ANGER. This metaphor 
suggests that the body of an angry person is the container for the emotion ANGER. Like a fluid in a container, ANGER can rise inside the body. An Increase in ANGER results in a rise of the fluid. To Hu (1993: 116), in English, human's body is conceived as an open container for emotion. This means, the container can be filled and /or overflowed with anger which is a kind of emotion.

\section{THE BODY IS A CONTAINER FOR THE EMOTIONS}

6) John was filled with anger.

To Kövecses (1990), this kind of metaphor conceptualizes the body or its parts as containers and the emotions as fluids and substances which are held in the containers. The central container-emotion metaphor is THE BODY IS A CONTAINER FOR EMOTIONS.

The ANGER IS HEAT metaphor, as applied to fluids, combines with the metaphor THE BODY IS A CONTAINER FOR THE EMOTIONS to produce the central metaphor of the system:

\section{ANGER IS THE HEAT OF A FLUID IN A CONTAINER:}

7) He had reached to the boiling point.

When there is no heat, the liquid is cool and calm. Thus, according to the metaphor ANGER IS THE HEAT OF A FLUID IN A CONTAINER, cool and calmness corresponds to lack of anger.

8) Keep cool. (Kövecses, 1986: 14)

In the conceptual metaphor ANGER IS THE HEAT OF A FLUID IN A CONTAINER, ANGER is the target domain and HEAT OF A FLUID IS IN A CONTAINER is the source domain. The target domain is more abstract than the source domain. The source domain is grounded in humans' experience. Based on the Conceptual Metaphor Theory (CMT), one experiential domain is mapped onto a different experiential domain so as to the second domain is partially understood in terms of the first domain. The domain that is mapped is called the source domain, and the domain onto which it is mapped, is called the target domain (Barcelona, 2003: 2011). We usually conceptualize the target domain through the source domain. We are mapping the knowledge from the source domain to the target domain. For example, we have knowledge about hot fluids when they start to boil, the fluid goes upward. This gives the entailment:

When the intensity of anger increases, the fluid rises.

9) We got a rise out of him.

It is also known that intense of heat produces steam and creates pressure on the container. This produces the metaphorical entailments:

Intense of anger produces steam.

10) Jack got all steamed up. 
Intense of anger produces pressure on the container.

\section{1)I was bursting with anger.}

When the intensity of emotion increases, the level of the fluid in the container rises. In case of having too much fluid in the container and the internal pressure is too high the fluid overflows the container or the container explodes. This means when anger becomes too intense, the person explodes as in (12). Thus, when a person explodes, what was inside him comes out.

12) When I told her, she just exploded.

To Kövecses (1986: 16-17), anger can be intense, that it can cause a loss of control, and that a loss of control can be dangerous to both the angry person and to those around him. The amount anger has a scale which is equal to the amount of heat scale. The anger scale is not open-ended; it has a limit point. It is just like a hot fluid in a closed container can only take much heat before it explodes. Thus, a person can bear much anger before he explodes, that is before he loses control. When anger gets more intense, the physiological effects increase and these increase interference with human's normal functioning. This means we lose our control over our functioning.

In the conceptual metaphor ANGER IS A HEAT OF FLUID IN A CONTAINER, there are a set of correspondences between the entities in the source domain and the entities in target domain. To Lakoff and Turner (1989: 62), the entities of the source domain are mapped onto the entities of the target domain. Moreover, to Barcelona (2003: 214), the mapping is unidirectional which means only the source is mapped onto the target domain:

Source domain: HEAT OF A FLUID IN A CONTAINER

-The container

-The heat of fluid

-Container heat

-Pressure in container

-Explosion

-Danger of explosion

- Coolness in the fluid

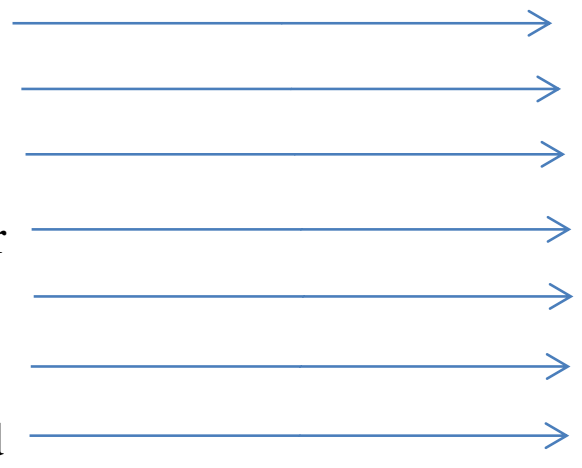

Target domain: HEAT

the body

the anger

body heat

internal pressure in the body

loss of control

danger of loss of control.

lack of anger. (Kövecses,

2002: 96)

Kurdish, like English, involves the use of the metaphorical conceptualization ANGER IS HEAT exactly as English does. Moreover, the two versions of the HEAT metaphor in English are applicable to Kurdish too. For instance, in (13) and (14), anger is conceived as HEAT OF FLUID IN A CONTAINER.

13) Pîyaweke hel'çu.

(The man overflowed) 
'The man overflowed with anger.'

14) Le tureyîan dekulì.

(He was boiling because of anger)

'He was boiling with anger.'

From all the examples discussed so far, body or the parts of body are viewed as a container for emotion, but this is not always the same. From the following examples, it can be seen, voice is conceptualized as an emotion container and emotions are viewed to be fluids and substances held in that container:

\section{ANGER IS A SUBSTANCE IN A CONTAINER}

15) There was a certain bitter anger in his voice.

The metaphors of anger with the CONTAINER source domain ANGER IS A FLUID IN A CONTAINER and ANGER IS A SUBSTANCE IN A CONTAINER instantiate two general metaphors: THE BODY IS A CONTAINER FOR EMOTATIONS and VOICE IS CONTAINER FOR EMOTIONS.

According to the second version of ANGER IS HEAT which is obtained when heat is applied to solids and we get ANGER IS FIRE.

16) She was breathing fire.

From the expression (16), we can see that anger can be conceptualized in terms of fire in two ways. The first one is that the body of a person who is angry is conceptualized as a container and it is filled with a fire burning inside. The second one is conceptualized as the fire burning outside the body which makes the container hot.

Just like the first version of the metaphor ANGER IS HEAT, there are many correspondences between the entities of the source domain and the entities of the target domain as follows:

Source: FIRE

Target: ANGER

-The fire is anger.

-The thing burning is the angry person.

-The cause of the fire is the cause of the anger.

-The intensity of the fire is the intensity of the anger.

-The danger of the fire to things nearby is the danger of the anger to other people (Kövecses, 1986: 19-20).

Kurdish, likewise, is full of the expressions which involve the second version of HEAT metaphor. In (17), the body of the angry person is conceived as the container which is burnt by fire and makes the container hot whilst in (18) the body of the angry person is conceived as the container which is filled with a fire burning inside.

17) Agrî girtibu le tureyan. 
(He caught fire because of anger)

'He was burning with anger.'

18) Agrî lê debarî le tureyan.

(Fire is falling from him because of anger)

'Fire is pouring out from him because of anger.'

On the other hand, in Kurdish, as it is seen in (19), voice is conceptualized as container for anger which is burnt by fire inside.

19) Qisekanî agrî lê debarî

(Fire was falling in his speech)

'Fire was pouring out of his speech.'

\subsection{ANGER IS INSANITY}

20)I just touched her, and she went crazy.

As the example (20) shows, in English, anger is conceptualized in terms of insanity. By metaphorical link between insanity and anger, the expressions that indicate insane behavior can also indicate angry behavior. From the metonymy INSANE BEHAVIOR STANDS FOR INSANITY and the metaphor ANGER IS INSANITY, the metaphorical metonymy can be gotten:

\section{INSANE BEHAVIOR STANDS FOR ANGER}

\section{1) She's fit to be tied.}

Moreover, violent frustrated behavior is conceived as a kind of insane behavior. People who can neither control nor relieve the pressure of anger engage in violent frustrated behavior. This idea is based on the metonymy:

\section{VIOLENT FRUSTRATED BEHAVIOR STANDS FOR ANGER}

22) The loud music next door has got me climbing the walls!

From the metaphor ANGER IS INSANITY, anger as the target domain can be understood from insanity which is the source domain. Here are some correspondences between them:

Source: INSANITY

- An insane person cannot function normally cannot function normally.

- An insane person is dangerous to others. A person who is angry beyond the limit point is dangerous to others.(Lakoff, 1987: 390-391)

In Kurdish, the same conceptual metaphor ANGER IS INSANITY is found. In (23), an angry person is conceived in terms of an insane person. The insane person who cannot function normally and is incapable of controlling his behavior corresponds to angry person.

23) Xot șêt meke.

Target: ANGER

A person who is angry beyond the limit point 
(Do not make yourself crazy)

'Do not go crazy.'

Moreover, the example (24) shows that insane behavior corresponds to angry behavior which is based on the metonymy INSANE BEHAVIOR STANDS FOR INSANITY.

24)Destaweșî meke.

(Do not hit me by hands)

'Do not hit me by hands like crazy.'

\subsection{ANGER IS AN OPPONENT IN A STRUGGLE}

25)I was struggling with my anger.

The metaphor OPPONENT has to do with control and the danger of loss of control to the angry person himself and to others. In the metaphor ANGER IS AN OPPONENEN IN A STRUGGLE, ANGER as the target domain is conceptualized in terms of STRUGGLE which is the source domain as follows

Source : STRUGGLE

-The opponent

-Winning

-Losing

-Surrender

\section{Target: ANGER}

anger.

controlling anger.

anger controlling you.

allowing anger to take control of you (Kövecses, 1990:

23).

In Kurdish, the OPPONENT metaphor is less common than the others. In (26), anger is conceptualized as an opponent and the angry person who is fighting with himself to control his anger corresponds to a person who fights with an opponent in the battle field to control and win the fight.

26) Katêk bê rêzî pêkirdim, bezehmet tiwanîm kontrolî xom bikem.

(When he disrespected me, I was hardly able to control myself.)

'When he disrespected me, I was hardly able to control my anger.'

\subsection{ANGER IS A DANGEROUS ANIMAL}

27) It is dangerous to arouse her anger.

This metaphor designates anger as a sleeping animal that is dangerous to awaken, something that needs to be controlled. There is a part of each person that is a wild animal. It is supposed to keep that part, which is the animal inside, private. The loss of control is equivalent to the animal getting loose. Thus, the behavior of a person who has lost control is the behavior of a wild animal. The following correspondences can be distinguished in this metaphor (Lakoff, 1987:392-393). 
Source: DANGEROUS ANIMAL

-The dangerous animal

-The animal's getting loose

-The owner of the dangerous animal

-The sleeping animal

-Being a wake for the animal
Target: ANGER

anger

loss of control of anger

the angry person

anger near the zero level

anger near the limit

The metaphor ANGRY BEHAVIOUR IS AGGRESSIVE ANIMAL BEHAVIOUR is considered as an instantiation of the ANGER IS A DANGERUOUS ANIMAL in which angry behavior as the target domain is conceptualized as aggressive animal behavior.

28)He was bristling with anger.

The aggressive behavior of the dangerous animal metaphorically corresponds to angry behavior, which in turn metonymically that aggressive behavior stands for anger. There are two metonymies for the ANIMAL metaphor:

\section{AGGRESSIVE VERBAL BEHAVIOR STANDS FOR ANGER}

29) He gave her a tongue-lashing.

\section{AGGRESSIVE VISUAL BEHAVIOR STANDS FOR ANGER}

30) She gave him a dirty look.

In the ANIMAL metaphors, sometimes, anger is understood in terms of some specific animals, such as a horse or a snake:

\section{ANGER IS A HORSE}

31) Her common sense is a bridle to her quick temper.

In the above examples, anger is conceptualized as a horse that is dangerous if it is not controlled. The pain that the horse may cause can be avoided if it is held under control. There are some correspondences in the ANGER IS A HORSE:

Source: HORSE

-The horse

-The bridles

-Being bridled for the horse

-Being unbridled for the horse

-The owner of the horse
Target: ANGER

anger

reasons

anger being under control

anger being out of control

the angry person

It has been experienced that an uncurbed horse is unsafe to ride. A horse may run at a dangerously high speed and it may throw off the rider or trample over him/her. Moreover, an unbridled horse may hurt the horse owner and others. The HORSE metaphor explains anger as it may hurt angry person and others if it is not controlled (Esenova, 2011: 57-59). 
Sometimes human's angry behavior is conceptualized in terms of aggressive horse behavior:

\section{ANGRY BEHAVIOR IS AGGREWSSIVE HORSE BEHAVIOR}

32) He bridled at the suggestion that he had been dishonest.

The above metaphor is considered as a subcategory of the metaphor ANGRY BEHAVIOR IS AGGRESSIVE ANIMAL BEHAVIOR in which the characteristic of aggressive horse behavior is mapped onto the angry human behavior.

Kurdish is unlike English in conceptualizing anger in terms of a specific animal. English conceives anger as a horse. In contrast, Kurdish conceives anger as a donkey and this yields the metaphor ANGER IS A DONKEY. In (33), anger is conceptualized as a donkey that is dangerous if it is not controlled. Donkey's territorial behavior, in case of not controlling, such as biting and kicking corresponds to an angry person's behavior. In (34), anger is conceptualized as donkey's aggressive behavior. This yields the metaphor ANGRY BEHAVIOR IS AGGRESSIVE DONKEY BEHAVIOR that is a subcategory of the metaphor ANGRY BEHAVIOUR IS AGGRESSIVE ANIMAL BEHAVIOUR.

33) Xot ker meke.

(Do not behave like a donkey)

'Do not make a donkey of yourself.'

34) Lêwişkan mawê.

(Do not kick out)

'Do not kick with hind legs.'

Moreover, in Kurdish, sometimes, anger is conceptualized in terms of some specific animal sound, such as donkey's bray, dog barking and lion's roar. This yields the metaphor ANGER IS AN AGGRESSIVE ANIMAL SOUND. In (35) anger is conceptualized as donkey's bray, in (36) as dog barking and in (37) as lion's roar. In this metaphor, for example in (35), donkey is mapped into an angry person and donkey's bray is mapped into expressing anger.

35)Piyaweke ke ture bu destîkird be zer̂in .

(The man started to bray because he was angry)

'When the man got angry, he started to bray.'

36) Del'êy sey hare, hemu kat pêm dewer̂ê.

'He is like a fierce dog, he always barks at me.'

37) Me nê̂êne.

'Do not roar.' 


\subsection{ANGER IS A SNAKE}

38) Anger at himself coiled within him.

39) But my anger coiled. Preparing its fangs.

The SNAKE metaphor is only found in English but not in Kurdish. This metaphor is a subcategory of the metaphor ANGER IS A DANGEROUS ANIMAL. In the SNAKE metaphor, anger as the target domain is conceptualized as snake which is the source domain. According to this metaphor, angry person is considered as a snake. In the ANGER IS A SNAKE metaphor, the knowledge that has been experienced from snake maps onto angry person. For example, the way of a snake preparing for a deadly attack, the snake coils up before striking the victim. Moreover, the snake opens its mouth and emits a hissing sound. Then the snake attacks the victim and kills it (Esenova, 2011: 60-61).

\subsection{ANGER IS A BURDEN}

40) He carries his anger around with him.

In the BURDEN metaphor, anger as the target domain is conceptualized in terms of burden that is the source domain. Sometimes, in English, responsibilities are metaphorized as burdens. Here, we have two types of responsibilities which are involved with anger. One of the types of responsibilities is related to controlling one's anger. The other type of responsibility is related to retributive justice that is constructed into human's concept of anger and it seeks revenge. To Lakoff (1987: 396), in case of angry retribution, there is a conflict between these two types of responsibilities. For instance, if we take out our anger on someone, we are not meeting our responsibility to control our anger, and if we do not take out our anger on someone, we are not meeting our responsibility to provide retribution.

Kurdish, on the other hand, shares the metaphor ANGER IS A BURDEN. In (41), anger is viewed as a heavy burden that is imposed on the angry person. Removing the heavy burden corresponds to the freedom from the feeling of anger. In the mentioned example, heart is a container which carries the burden, but in (42) the whole body is conceived as a container which carries the burden.

41) Ke qisey dil'î xom hel'rișt, îŝrahetim kird.

(When I unloaded the words of my heart, I was relieved)

'When I expressed my anger, I relaxed.'

42) Ke ture debî, çon xot betal' dekeyawe?

(When you are getting angry, how do you empty yourself?)

'How do you unload your anger when you are getting angry?' 


\subsection{ANGER IS A PLANT}

In English, as in (43), anger as the target domain is conceived as a plant which is the source domain in the PLANT metaphor. This metaphor is not found in Kurdish.

43) After this, depression sets in and deep seated anger can take root.

The PLANT metaphor has been grounded in human's agriculture experience. In this metaphor various stages of plant growth correspond to various stages of anger development. The seed image as the first stage of plant growth corresponds the existence of anger. In the source domain, the germination and plant taking root in the early stages of plant growth correspond to the early stages of anger development in the target domain. Furthermore, bloom as the best stage of plant growth, according to humans view, corresponds to the best stage of anger development. Also, the fruition stage of the plant growth corresponds to the stage of anger development when the emotion leads to a concrete result. Lastly, as the plant stops growing and it dies which is the last stage of plant life corresponds to the last stage of anger development as anger ceases to exist (Esenova 2009:4.2).

\subsection{ANGER IS A CHILD}

This metaphor does not exist in Kurdish, but it is found in many expressions in English. For example:

44) Instead she decided to nurse her anger.

In (44), anger as the target domain is conceptualized in terms of child which is the source domain. In the CHILD metaphor, the stages of child gestation correlate with the stages of anger development. For example, the embryonic stage which is the initial stage in the child's prenatal growth corresponds to the early stage of anger development. The metaphorical explanation in (44) which indicates the final stage of child's growth in the uterus corresponds to the late stage of anger development (Esenova 2011: 47-48).

45) He is pregnant with rage, and his pains are coming closer.

\subsection{ANGER IS A DEVIL}

46) She was possessed by devil.

In the DEVIL metaphor, anger is the target and devil is source domain. In English, as in (46), anger is conceptualized in terms of devil. This metaphor is considered as a special kind of POSSESDO NOTSION metaphor that was first described by Lakoff and Johnson (1999: 269-274). According to them, POSSESSION metaphor is a system of classification of the Self in which we believe that ourselves as a double unit is composed of one Subject and one or more Selves. The Subject corresponds to the part of the person that experiences consciousness, reason, will and judgment. The metaphor TAKING CONTROL OF ANOTHER SELF IS TAKING ANOTHER'S POSSESSION is one of the versions of the POSSESSION metaphor 
which includes the notion of "possession" of one's body by another subject, typically, devil, an alien or a spirit being evil possession.

Kurdish shares the conceptual metaphor ANGER IS A DEVIL. As in (47) and (48), in Kurdish, it is believed that it is the devil that controls an angry person. When someone becomes very angry and behaves like an insane, it is said:

47)Le kelî șeytan were xwarê.

'get off from the devil's hilltop'

48) Șeytan swarî serî biwa.

'Devil has been on his head.'

\subsection{ANGER IS A BAD SMELL/ TASTE}

English and Kurdish share the conceptual metaphor ANGER IS A BAD TASTE and ANGER IS A BAD SMELL. Esenova (2011: 63-66) explains the BAD SMELL and BAD TASE metaphor. According to her, in English, sometimes, people experience anger in terms of bad smell and/ or bad taste. For example, ANGER IS A BAD SMELL conceptualizes anger in terms of an offensive odour whereas ANGER IS A BAD TASTE conceptualizes anger as unpleasant taste, such as: bitter, sour and overly salty. In (49), anger as an unpleasant emotion is conceptualized in terms of an unpleasant odour.

49) He has seen their cruelty, smelt their putrid anger.

In the BAD SMELL metaphor, the following ontological correspondences can be identified:

Source domain: BAD SMELL

-Bad smell

-Giving off a bad smell

-Unpleasantness of the smell to the sense

-Smelling a bad odour
Target domain: ANGER

anger

having anger

unpleasantness of anger to the mind detecting anger

In English, in (50), anger is conceptualized as a sharp unpleasant taste. The unpleasantness of the taste to the senses corresponds to the unpleasantness of anger to the mind. This metaphor is motivated by human's perception of certain tastes such as sour and bitter that are experienced to be unpleasant.

50) He was full of bitterness after he lost his job.

On the other hand, in Kurdish, in (51), anger is conceived as the taste of chili pepper. An angry person corresponds to a person who eats pepper and as the result of that this person feels hot in his mouth. Furthermore, in (52), voice is concerned as the container and anger is conceived as the smell of blood in the container.

51) Hêwașbe! Del'êy bîberit xiwaridiwe.

'Easy! You seem to have eaten pepper.' 
52) Qisekanî bonî xiwênî lê dêhat.

'His words smelt of blood.'

The following ontological mappings are found in the metaphor ANGER IS A BAD TASTE:

Source domain: BAD TASTE

- Bad taste

-Unpleasantness of the taste to the sense
Target domain: ANGER

anger

unpleasantness of anger to the mind

\subsection{ANGER IS A NATURAL FORCE}

The FORCE metaphor is found in English, but not in Kurdish. In English, sometimes, anger the target domain is conceptualized in terms of force which is the source domain. Though, someone can distinguish different classes of forces that angry people are able or unable to control. For example, ANGER can be conceptualized as a natural force which yields the metaphor ANGER IS A NATURAL FORCE. According to Kövecses (1990), the main focus of this metaphor is lack of personal control over the emotion. In (53), anger is conceived as a storm.

53) There was a stormy meeting.

\subsection{ANGER IS A CAPTIVE ANIMAL}

In English, sometimes, people conceptualize anger as an animal kept in a prison. This yields the metaphor ANGER IS A CAPTIVE ANIMAL (Kövecses, 2000: 21). In contrast, this metaphor is not found in Kurdish. The metaphor ANGER IS A CAPTIVE ANIMAL has to with controlling or losing control over anger. In (54), anger which is the target domain is conceived as an animal that is released in a prison. The released animal in the prison corresponds to loss of control over anger. Moreover, keeping the animal in the prison corresponds to controlling anger. This metaphor overlaps with the ANGER IS A DANGEROUS ANIMAL metaphor, as I discussed before in which the loss of control could be dangerous for both the angry person and the others around him.

54) She unleashed her anger.

\subsection{ANGER IS BLINDNESS}

English does not share this metaphor. It is only found in Kurdish. In the BLINDNESS metaphor, anger is the target domain and blindness is the source domain. In the examples (55-57), anger is conceived as blindness. A person who is blind corresponds to an angry person. Moreover, a person who is blind and incapable of finding out his way corresponds to an angry person who cannot control his anger.

55) Le tureyan kiwêr bum.

(I was blind because of anger) 
'I was blind with anger.'

56) Her ke pencey lê raweşandim, dinîyam leber çawan tarîk bu.

'When he shook his finger at me, the world got dark in front of my eyes.'

57) Ke cinêwî pêdam, çawim hîçî nebînî.

'When he swore at me, my eyes did not see anything.'

\section{Conclusions}

The present study shows that both English and Kurdish share many metaphorical expressions of anger. The similarities are attributed to the universality of conceptual metaphors of anger and similar experiences. In contrast, differences in metaphorical expressions of anger are related to cultural- specific ways in English and Kurdish.

English and Kurdish share some conceptual metaphors of anger. For example, the HEAT metaphor is the largest and most common metaphorical conceptualization for anger in both English and Kurdish. The languages share both versions of HEAT metaphor: ANGER IS FIRE and ANGER IS THE HEAT OF FLUID IN A CONTAINER. Also the metaphors ANGER IS INSANITY, ANGER IS AN OPPONENT IN A STRUGGLE, ANGER IS A DANGEROUS ANIMAL, ANGER IS A BURDEN, ANGER IS A DEVIL and ANGER IS A BAD TASTE/ BAD SMELL can be found in both languages.

Despite of having some similar points about the conceptualization of anger in English and Kurdish, but also some distinctions can be drawn between them. For example, the metaphors ANGER IS A SNAKE, ANGER IS A PLANT, ANGER IS A CHILD, ANGER IS A NATURAL FORCE and ANGER IS A CAPTIVE ANIMAL can only be found in English but not in Kurdish. In contrast, the metaphors ANGER IS BLINDNESS and ANGER IS AN ANIMAL SOUND can be found in Kurdish but not in English.

Moreover, in the ANIMAL metaphor, English conceives anger in terms of horse, but Kurdish conceives anger in terms of donkey.

\section{Appendix A}

\section{Kurdish phonemic symbols for consonants sounds}

/p/ per /porR/ 'paper'

/b/ bon /bpn/ 'smell'

/t/ tak /tæk/ 'odd'

/d/ dar /dar/ 'tree'

/k/ ker /kər/ 'donkey'

/g/ gerim /gərim/ 'hot'

/q/ qul' /qut/ 'deep'

/P/ eme /Pmo/ 'this' 
/f/ fer̂iş /fəRIf/ 'carpet'

/v/ vêla /velæ/ 'villa'

/s/ ser /sər/ 'head'

/z/ zar /zær/ 'mouth'

/S/ şar / / ær/ 'city'

/3/ jîyan /zîan/ 'life'

/x/ xew /xəw/ 'sleep'

/y/ ̈̈az /yæz/ 'gas'

/h/ hekem /həkəm/ 'judge'

/S/ 'elaq /Səlaq/ 'barber'

/h/ hêz /hez/ 'power'

/gf/ Çiwar /Çrwær/ 'four'

/l/ lar /lær/ 'slope'

/ḑ̧/ cîl / dżi:1/ 'generation'

/t/ l'al' /łæl/ 'dumb'

$/ \mathrm{m} /$ mar /mær/ 'snake'

/n/ nan /næn/ 'bread'

/r/ parê /pærə/ 'money'

/R/ rubar /Rubær/ 'river'

/w/ wișe /wifa/ 'word'

/j/ yar /jær/ 'lover'

\section{Appendix B}

Kurdish phonemic symbols for vowel sounds
/i:/ șîr / /fi:r/ 'milk'
/i/ birdî /birdi/'he took'
/I/ xiwardin /xıwærdın/ 'eating'
/e/ xêr /xer/ 'charity'
/a/ derga /dərgæ/ 'door'
/a:/ kar /ka:r/ 'job'
/v/ kun /kon/ 'hole'
/u:/ nûsîn /nu:si:n/ 'writing'
/p/ kon /kpn/ 'old' 


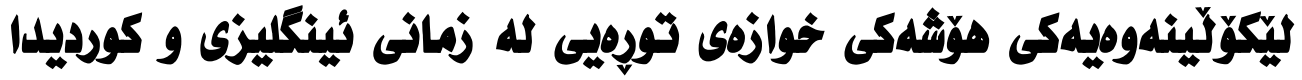

\section{خالل على عبدالله}

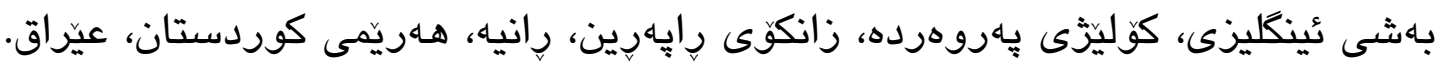
طيمهيل:uozhin@uor.edu.krd

ئهم تويَزينهوهيه، تويَزَينهوهيهكى بهراوردكارى خوازهى تورهييه له هـردووك زمانى ئينكليزى و كورديدا

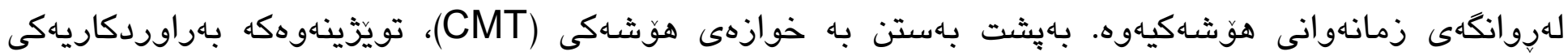

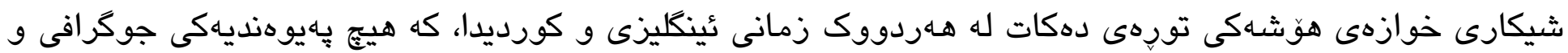

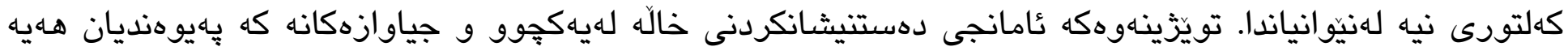

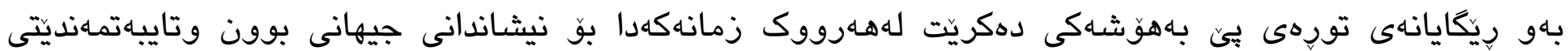

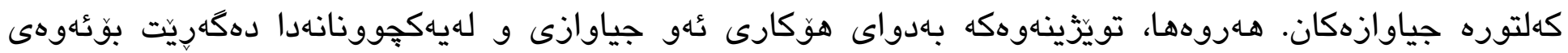

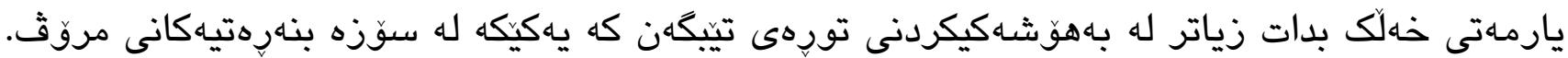

كليله وشهكان: تورهى، خوازهى هوَشهكى، دركهى هوَشهكى، ئينكليزى، كوردى. 


\section{References:}

Ansah, G. 2011. Metaphor and Bilingual Cognition: The Case of Akan and English in Ghana.

Doctoral dissertation. Lancaster University.

Barcelona, Antonio. (2003). "Metaphor and Metonymy in Comparison and Contrast”. In R. Dirven

\& R. Pörings (Eds.). Clarifying and applying the notions of metaphor and metonymy within cognitive linguistics. Berlin/ New York: Mouton de Gruyter, 207-277.

Cruse, Alan. (2000). Meaning in Language: An Introduction to Semantics and Pragmatics. United

States Oxford University Press Inc.

Evans, Vyvyan. (2006). "Language and Cognition: The View from Cognitive Linguistics".

Language and Bilingual Cognition. Amsterdam: John Benjamins, 69-108.

Esenova, O. 2009. Anger metaphors in the English language. Studies in Variation Contacts and

Change in English, 3. Available at: http://www.helsinki.fi/varieng/journal/volumes/03/esenova/. Accessed on $\{10 / 5 / 2020\}$

Esenova, O. 2011. Metaphorical Conceptualization of Anger, Fear and Sadness in English.

Doctoral dissertation. ISBN: 978-91-86545-01-7. Printed by CA\&CC Press® AB, Luleå, Sweden

Hamawand, Zeki. (2008). Morpho-Lexical Alternation in Noun Formation. London: Palgrave Macmillan.

Hamawand, Zeki. (2011). Morphology in English. Word-formation in Cognitive Grammar.

London. Continuum International Publishing Group.

Hu, Ying-Hsueh. 1993. A Cross-cultural Investigation of Conceptual Metaphors of Emotion.

Unpublished Manuscript. University of Edinburgh.

Kövecses, Z. 1986. Metaphors anger, pride, and love: A lexical approach to the structure of concepts. Philadelphia: John Benjamins. https://doi.org/10.1075/pb.vii.8 
Kövecses, Z. 1990. Emotion concepts. New York: Springer-Verlag. https://doi.org/10.1007/978-1 $4612-3312-1$

Kövecses, Z. 2000. Metaphor and Emotion: Language, Culture, and Body in Human Feeling. Cambridge: Cambridge University Press.

Kövecses, Z. 2002. Metaphor: A Practical Introduction. Oxford: Oxford University Press.

Lakoff, G. \& M. Johnson. 1980. Metaphors We Live By. Chicago: The University of Chicago Press.

Lakoff, G. 1987. Women, fire, and dangerous things: What categories reveal about the mind. Chicago: University of Chicago Press. https://doi.org/10.7208/chicago/9780226471013.001.0001 Lakoff, G. and Turner, M. (1989). More than Cool Reason: A Field Guide to Poetic Metaphor. Chicago and London: The University of Chicago Press.

Lakoff, George \& Kövecses, Zoltán (1987a). "Case Study 1: Anger ", in: Lakoff, George (1987), $380-415$.

Lakoff, G. \& Johnson, M. (1999). Philosophy in the Flesh: The Embodied Mind and its Challenge to Western Thought. New York: Basic Books.

Langacker, Ronald (1987). Foundation of Cognitive Grammar. Vol. 1: Theoretical Prerequisites. Stanford: Stanford University Press.

Langacker, Ronald (2010). “Conceptualization, Symbolization, and Grammar”. International Journal of Cognitive Linguistics. V 1, Issue 1, p. 31-63. Nova Science Publishers, Inc.

Taylor, John. (2002). Cognitive Grammar. Oxford: Oxford University Press. 